research in human subjects must be reviewed and approved by the local institutional review board before the Department of Health and Human Services will even consider whether they should be funded. Nevertheless, by regulation, the Department of Health and Human Services is required to repeat some of the institutional review board's activities; for example, the department must repeat the evaluation of the relation between risks and benefits. The institutional review board does not have the authority to approve certain categories of research specified in the regulations-for example, research in children in which "more than minor increases over minimal risk" are presented by "an intervention or procedure that does not hold out the prospect of direct benefit" for the child subject. Research in these categories can be approved only by the secretary of the Department of Health and Human Services in consultation with a panel of experts and after an opportunity for review and comment by the public. To the best of my knowledge there are no similar activities at national level in the United Kingdom, although they have been advocated by Mary Warnock and others. ${ }^{2}$

Agents of the United States Food and Drug Administration conduct routine inspections of the institutional review boards and investigators engaged in the review or conduct of research on drugs, medical devices, and other "test articles" regulated by the administration. Inspections by officials of the United States Department of Health and Human Services may also occur in response to reports of "serious or continuing noncompliance."

Federal regulations require that each institutional review board should have "at least one member who is not otherwise affiliated with the institution." Many states require public institutions to open their meetings to the public, and some private institutions similarly open their meetings. Though few "outsiders" seem to attend meetings of the institutional review boards, these policies serve to remind the members of their ultimate accountability to the public. Spokespersons for institutional review boards engaged in reviewing activities of great interest to the media - for example, the implantation of a baboon's heart in "Baby Fae"3 and of the first totally artificial heart ${ }^{4}$-have reported that the presence of journalists has been highly disruptive.

In response to apparent ethical improprieties in the conduct of clinical research several British commentators-for example, Byrne, ${ }^{5}$ Faulder, ${ }^{6}$ and Nicholson ${ }^{7}$ - have called for reform in the British system of ethical oversight in research. In their view Britain should adopt a system similar to that in place in the United States. Elsewhere I have suggested that the American system of regulation reflects its unique recent social history and distinctively individualistic ethos. ${ }^{8}$ For this reason other societies may find some of the United States' policies and practices unsuitable for their needs.

Professor of Medicine,

ROBERT J LEVINE

Yale University School of Medicine

New Haven, Connecticut 06510,

United States

1 Levine RJ. Ethics and regulation of clinical research. 2nd ed. Baltimore: Urban and Schwarzenberg, 1986.

Warnock M. A national ethics committee. Br Med f 1988;297:1626-7.

3 Sheldon R. The IRB's responsibility to itself. Hastings Center Report 1985;15:11-2.

4 Working Group on Mechanical Circulatory Support of the National Heart, Lung, and Blood Institute. Artificial heart and assist devices: directions, needs, costs, societal and ethical issues. Institute. Artificial heart and assist devices: directions, needs,

5 Byrne P. Medical research and the human subject: problems of consent and control in the UK experience. Ann NY Acad Sci 1988;530:144-53.

6. Whess, 1985.

Nicholson RH, ed. Medical research with children. Oxford: Oxford University Press, 1986.

8 Levine RJ. Protection of human subjects of biomedical research in the United States: a contrast with recent experience in the United Kingdom. Ann NY Acad Sci 1988;530:133-43.

\title{
The contraceptive pill and breast cancer in young women
}

\author{
Evidence is still reassuring
}

Last week saw yet more press headlines about the contraceptive pill and breast cancer. Yet as the number of epidemiological studies on the effect of oral contraceptives on breast cancer has increased the picture remains far from clear. This lack of consensus contrasts with other studies on the contraceptive pill. For example, at least nine case-control studies have agreed that combined oral contraceptives reduce the risk of endometrial cancer, and at least eight case-control studies have shown a reduced risk of ovarian cancer. ${ }^{1}$ A protective effect against uterine and ovarian cancers is biologically plausible because combined oral contraceptives abolish the rapid cellular proliferation that occurs every month in these organs.

An effect of combined oral contraceptives on the incidence of breast cancer is also biologically plausible. The fact that the risk of breast cancer is increased by an early menarche and by a late menopause ${ }^{1}$ implicates ovarian steroids in the initiation or promotion, or both, of breast cancer. What is far from clear on theoretical grounds is whether combined oral contraceptives can be expected to enhance or to antagonise these harmful effects of ovarian activity. The ovary produces its hormones sequentially - first oestrogen then progesterone-but combined oral contraceptives provide them simultaneously. If unopposed oestrogen is a risk factor for breast cancer (as it is for endometrial cancer) combined oral contraceptives should diminish breast cancer risk, but no such effect has been observed in epidemiological studies. Breast lobules do not proliferate during the menstrual cycle, but cell turnover increases in the second half of the cycle..$^{3-5}$ The pattern of cell turnover in the breast is not affected by combined oral contraceptives. ${ }^{45}$

The theoretical uncertainty has been reflected by conflicting results from epidemiological studies. Of the many studies published so far, none has suggested that combined oral contraceptives protect against breast cancer and most have failed to show any effect of combined oral contraceptives on the risk of breast cancer. ${ }^{6-9}$ Some have shown an increased risk associated with the use of the contraceptive pill early in life or before the first pregnancy while showing no risk associated with the use of combined oral contraceptives later in the reproductive years. ${ }^{6}{ }^{10}$ Studies which have concluded that the use of combined oral contraceptives carries risks tend to have been scrutinised more critically than those with reassuring results, but in general both studies giving negative results and those giving positive results have been conducted with equal care and there is no obvious explanation for their different results. ${ }^{1671112}$

Last week saw the publication in the Lancet of a.casecontrol study in 11 areas of Britain of 755 women with breast cancer that had been diagnosed before the age of $36 .{ }^{13}$ Cases 
and matched controls were interviewed about their contraceptive histories. Similar studies have been criticised in the past because recall or observer bias may arise when interviewers know which women are cases and which are controls. ${ }^{14}$ To reduce this bias interviews in the recent study were structured and combined with scrutiny of general practitioners' notes and family planning clinic records. An association was found between the duration of use of combined oral contraceptives and the risk of breast cancer, with a relative risk of 1.74 after more than eight years' use of such contraceptives.

In contrast to previous studies this association was seen whatever the age at which the combined oral contraceptive was taken and was seen with use both before and after the first full term pregnancy. This is surprising: previous studies have found no risk associated with the use of combined oral contraceptives in older women. Another new finding was the suggestion of a link between cancer risk and the dose of oestrogen: contraceptives containing less than $50 \mu \mathrm{g}$ ethinyloestradiol carried less of a risk, though some risk was still detectable even with low dose pills.

An important aspect of the study was that it was restricted to women with breast cancer that had been diagnosed before the age of 36. This was to ensure that both cases and controls had had the opportunity of taking combined oral contraceptives at a young age-indeed, $91 \%$ of cases and $89 \%$ of controls had taken such contraceptives at some time in their lives. Because of this restriction, however, the results may not be relevant to most women with breast cancer. Breast cancer before the age of 36 is rare and may have different risk factors from the much more common late onset tumours. There are epidemiological differences between early and late onset breast cancer ${ }^{15}{ }^{17}$ - for example, the effect of early menarche is less in postmenopausal cancer. ${ }^{2}$ Early onset breast cancer may be a more aggressive disease than late onset cancer, and exogenous hormones may have more influence when tumour initiation has occurred early in reproductive life.

The new low dose combined oral contraceptives are known to be safer than older preparations with respect to cardiovascular disease, and this study indicates that the same may apply to breast cancer. This is biologically plausible, because the risks or benefits of the use of combined oral contraceptives relative to ovarian activity depend on the amounts and types of steroid they provide compared with those produced by the ovary. Combined oral contraceptives in current use contain low doses of both oestrogen and progestogen, and the finding in this study that the low dose pill seems to be less harmful than older high dose preparations raises the possibility that the progestogen dosage might also be important. Different preparations, however, contain different progestogens (with differing potencies), and no conclusions can yet be drawn about progestogen type or dosage.

Nevertheless, the study found a protective effect of the progestogen only pill. This is particularly interesting because until now there has been very little information about the effect of these pills on cancer risk. The biological fact that the breast tends to be more active in the second half of the normal cycle might have suggested that progestogen pills would have an adverse effect on the incidence of breast cancer. ${ }^{3418}$ The study's findings on progestogen pills clearly require confirmation, and they emphasise the difficulty of predicting the effects of hormones on a theoretical basis.

Finally, the way studies like this are presented to the public is important. Studies that find negative results or show the health benefits of combined oral contraceptives tend to receive little attention - a truth illustrated last month by the silence that greeted two studies that gave negative results. ${ }^{12}$ As a result women now have exaggerated fears about the dangers of combined oral contraceptives. ${ }^{19}$ Breast cancer is an emotive disease, and the contraceptive pill is still newsworthy even after 25 years, presumably because of its sexual associations. Breast cancer may soon be overtaken by lung cancer as the commonest malignancy among women, but this avoidable increase in lung cancer in women does not seem to be a health issue, perhaps because it is no longer controversial. By contrast the continuing uncertainty about the contraceptive pill and breast cancer will keep this issue in the public eye for some time to come, even though the weight of the evidence is still reassuring - for as the authors of the new study point out, there is no support for their findings in national breast cancer registration rates, which are not increasing. ${ }^{13}$

\section{JAMES OWEN DRIFE}

Senior Lecturer in Obstetrics and Gynaecology,

Leicester Royal Infirmary,

Leicester LE2 7LX

1 Vessey M. Oral contraception and cancer. In: Filshie M, Guillebaud J, eds. Contraception: science and practice. London: Butterworth, 1989:52-68.

Kampert JB, Whittemore AS, Paffenbarger RS. Combined effect of childbearing, menstrual events, and body size on age-specific breast cancer risk. Am f Epidemiol 1988;128:962-79.

3 Masters JRW, Drife JO, Scarisbrick JJ. Cyclic variation of DNA synthesis in human breast epithelium. FNCI 1977;58:1263-5.

4 Anderson TJ, Ferguson DJP, Raab GM. Cell turnover in the "resting" human breast: influence of parity, contraceptive pill, age and laterality. Brf Cancer 1982;46:376-82.

5 Going JJ, Anderson TJ, Battersby S, McIntyre CCA. Proliferative and secretory activity in human breast during natural and artificial menstrual cycles. Am $\mathcal{F}$ Pathol 1988;130:193-204.

6 Anonymous. Cancer risks of oral contraception [Editorial]. Lancet 1989;i:21-2.

7 Schlesselman JJ, Stadel BV, Murray P, Lai S. Breast cancer in relation to early use of oral contraceptives. JAMA 1988;259:1828-33.

8 Rohan TE, McMichael AJ. Oral contraceptive agents and breast cancer: a population-based case-control study. Med f Aust 1988;149:520-6.

9 Prentice RL, Thomas DB. On the epidemiology of oral contraceptives and disease. Adv Cancer Res 1987;49:285-401

10 McPherson K, Vessey MP, Neil A, Doll R, Jones L, Roberts M. Early contraceptive use and breast cancer: results of another case-control study. Brf Cancer 1987;56:653-60.

11 McPherson K, Drife JO. The pill and breast cancer: why the uncertainty? Br Med $\mathcal{F}$ 1986;293 $709-10$.

12 Anonymous. Cases/controls, breast cancer and the pill [Editorial]. Lancet 1989;i:1000.

13 UK National Case-Control Study Group. Oral contraceptive use and breast cancer risk in young women. Lancet 1989;i:973-82.

14 Drife JO. Which pill? BrMed f 1983;287:1397-8.

15 Janerich DT, Hoff MB. Evidence for a crossover in breast cancer risk factors. Am $\mathcal{f}$ Epidemiol 1982;116:737-42.

16 Pathak DR, Speizer FE, Willett WC, Rosner B, Lipnick RJ. Parity and breast cancer risk: possible effect on age at diagnosis. Int 7 Cancer 1986;37:21-5.

17 Negri E, La Vecchia C, Bruzzi P, et al. Risk factors for breast cancer: pooled results from three Italian case-control studies. Am $\mathcal{F}$ Epidemiol 1988;128:1207-15.

18 Milligan D, Drife JO, Short RV. Changes in breast volume during normal menstrual cycle and after oral contraceptives. Br Med J 1975;iv:494-6.

19 Grubb GS. Women's perceptions of the safety of the pill: a survey in eight developing countries. f Biosoc Sci 1987;19:313-21. 